\title{
Honey, Food and Medicine: Scientific Rationale and Practical Efficiency in External Administration of Medicinal Honey for Wound Healing
}

\author{
Andrei Zbuchea \\ Plastic Surgery Department, Emergency District Hospital, Ploiesti 100097, Romania
}

\begin{abstract}
Except for its benefits as food and medicine, honey has been used since ancient times as an external remedy in wound care, and has been the subject of numerous studies and research, that reveal its complex favorable action for wound healing. Based on scientific research and clinical studies published in literature, this work presents these various properties and therapeutic activities of honey dressings. Next, actions and clinical effects of L-Mesitran range of dressings, based on medicinal honey and authorized European Union (EU) and Food and Drug Administration (FDA), have been highlighted in a case series of patients in the Department of Plastic Surgery, Emergency District Hospital of Ploiesti, Romania, by monitoring the clinical local evolution of burns and other wounds. L-Mesitran range of products is based on the combination of medicinal honey and other ingredients, such as hypoallergenic medicinal lanolin, vitamins C and E. These sterilized preparations were applied for various skin lesions after wound cleansing, and exerted a favorable action on healing of burns and other wounds, sometimes in combination with surgical treatment, being applied in these cases before or after surgery. Further clinical studies are needed to establish the best indications, methods and forms of administration for each type of wounds, as well as the selection over other types of dressings.
\end{abstract}

Key words: Medicinal honey, L-Mesitran, burns, efficiency, wound healing.

\section{Introduction}

Honey is a unique and invaluable product of bees, derived mainly from the nectar of flowers, which has been used both as food and medicine since the beginning of human civilization. Honey bees with their main products, honey and wax, acquired artistic, literary, mythological, religious, nutritive, medical, scientific, agricultural, technical, industrial, cosmetic, occupational, leisure, philosophical valences and preoccupations. Among bee products, especially honey and beeswax closely accompanied human history, culture and civilization.

Honey appears as a medicine in the earliest known written documents, such as clay tablets of Mesopotamian culture, dating back to 2700 BC. Over time, honey has been accepted as one of the most precious foods and medicines. It was mentioned in

Corresponding author: Andrei Zbuchea, Ph.D., research fields: burns, wound healing and apitherapy.
Bible, Koran and Talmud, and it gained special attention from the Romans, the Greeks and the Egyptians. In fact, the faith in miraculous and healing power of honey was encountered in every territory populated by bees [1].

In conjunction to its value and importance as a food, honey has also been used over time as a practical and efficient medicine, administered both orally and externally. Thus, honey can establish a clear evidence of the principle attributed to Hippocrates, the Father of Medicine: "Let food be thy medicine and medicine be thy food”.

Besides internal administration for health improvement, honey has been used since ancient times in external applications for the treatment of various types of wounds. Honey was regarded as "the oldest wound dressing material known to medicine” [2] and was used systematically over time for wound treatment, besides its benefits as food and medication. 
In modern types, honey was "rediscovered" as a potent remedy for wound healing and was the subjects of many laboratory research and clinical studies, which highlighted its multiple properties and actions favorable to wound healing: antibacterial, anti-inflammatory, anti-edematous, antioxidant; free radicals control; providing moist local environment; debridement of the wound; increasing the rate of healing and nourishing action.

Due to modern bacterial rising of antibiotic resistance, an essential argument for honey use in wound therapy is the remarkable anti-infectious activity, without development of bacterial resistance or emergence of mutants resistant to honey [3-6].

\section{Materials and Methods}

The scientific rationale that supports the use of honey for wound healing has been highlighted by thorough analyses and synthesis on available data from literature, like Medline and other databases, journals collections: Burns, Annals of Burns and Fire Disasters, search engines, review articles, specialized books, without restrictions regarding the source or date of publication, being selected the most representative and reliable studies.

Besides the data published in literature, this work material presents a series of clinical outcomes from the Department of Plastic Surgery, Emergency District Hospital of Ploiesti, Romania, by using L-Mesitran range of dressings, based on medicinal honey, authorized European Union (EU) and Food and Drug Administration (FDA). The actions and clinical effects of these products based on medicinal sterilized honey have been highlighted in a lot of patients admitted in the Department of Plastic Surgery, by monitoring the clinical local evolution of burns and other types of wounds. The dressings were changed daily and L-Mesitran products were applied after removal of dressings and wound cleansing. Decreasing inflammatory and infectious signs, elimination of detritus, wound healing rate and epithelization, concomitant medication, patient satisfaction and also side effects were investigated.

\section{Results and Discussion}

A lot of scientific studies and experimental research certified the complex activity of honey in wounds, induced by unique and synergic aggregation of useful properties and effects, such as anti-infectious, anti-inflammatory, antiexudative, antioxidant, wound healing, wound debriding and nutritional.

\subsection{The Anti-infectious Activity of Honey}

Honey is a traditional therapy for infected wounds. Its anti-infectious property was highlighted by many laboratory studies. Honey has exhibited very broad-spectrum anti-infectious action against at least 80 species of micro-organisms, including Gram-positive and Gram-negative bacteria, aerobes and anaerobes [7-11] (Table 1). Moreover, minimum inhibitory concentration (MIC) was generally below $10 \%$, which is usually inferior to concentration of honey in wounds, where it can be diluted by wound exudates [12-15].

Table 1 The anti-infectious spectrum of honey.

\begin{tabular}{ll}
\hline No. & Anti-infectious spectrum \\
\hline 1 & Gram-positive bacteria: Staphylococci including methicilin resistant (MRSA) and coagulase negative \\
2 & Staphylococcus aureus [7, 8] \\
3 & Helicobacter pylori \\
4 & Mycobacterium tuberculosis \\
5 & Gram-negative bacteria: Pseudomonas aeruginosa, Escherichia coli, Acinetobacter \\
6 & Anaerobic bacteria \\
7 & Fungi: Aspergillus, Penicillium, all the common dermatophytes \\
\hline
\end{tabular}


The application of honey in infected wounds acquired an increasing interest, as result of the widespread development of bacterial resistance to antibiotics, as well as of the evidence that honey is highly effective against such antibiotic-resistant bacteria [16]. No loss of bacterial sensibility to honey and no appearance of bacteria resistant mutants were evidenced in time [17]. Moreover, bacteria aggregated in biofilms are sensitive to honey [3, 18-21] and resistant to antibiotics and silver dressings [22]. It might explain why honey succeeded in many cases, where other antibacterial therapies failed [23, 24].

Honey is the only food product that can be stored and preserved in its natural and original state, without processing or addition of preservatives, for very long periods of time, even several years, without alteration, even if honey could be contaminated with some microorganisms. Nevertheless, the development of microorganisms is prevented by the specific features of honey, high osmotic pressure (high glucidic content) and high acidity (low $\mathrm{pH}$ ) [10, 25]. As a result, only some types of bacteria and fungi are capable to survive within honey environment and the population of microorganisms is remarkably stable during storage. Moreover, some of bacteria found in honey can produce antimicrobial agents called bacteriocins, which can protect honey against further development of other microorganisms and are beneficial for people's health [10, 26].

The complex and broad anti-infectious ability of honey can be explained by multiple and synergic mechanisms of actions, different from antibiotics. Unlike honey, antibiotics have limited and specific mechanism of action, by destroying the bacteria's cell wall or by inhibiting intracellular metabolic pathways [11].

The anti-infectious property of honey can be related to an association of properties: hygroscopicity, hyperosmolarity, acidity, peroxide content and antibiotic activities due to phytochemical factors [11, 27].
The antibacterial property of honey, recognized in 1892 by the Dutch scientist Van Ketel [28], was attributed entirely to the osmotic effect of high glucidic content [28-31], which leads to drawing moisture from the environment and to dehydrating bacteria [11]. Honey has such a high level of osmolarity that it is able to inhibit microbial growth [11, 32].

Besides hygroscopicity and hyperosmolarity, the acidity of honey, which is provided by organic acids (e.g., gluconic acid), is another factor contributing to its anti-infectious activity [10]. The $\mathrm{pH}$ level of honey, generally ranging from 3.2 to 4.5 , is low enough to inhibit the growth of most microorganisms [11]. The acidity of honey can also contribute to the antibacterial action of macrophages, since an acidic $\mathrm{pH}$ inside the vacuole is involved in destroying the ingested bacteria [33].

Other elements can also concur to the anti-infectious property of honey. Honey contains a factor which was named "inhibine" before its acknowledgment as hydrogen peroxide, an effective antimicrobial agent which is delivered by the enzyme glucose oxidase in honey [34], secreted by the hypopharyngeal glands of bees. Under the action of glucose oxidase, glucose undergoes oxidation to gluconolactone and hydrogen peroxide. Hydrogen peroxide is probably the most important antibacterial factor, although some authors consider the nonperoxide activity to be more significant [11].

Lastly, a lot of phytochemical components can concur to the anti-infectious capability of honey. Additional non-peroxide antibacterial factors were identified in some honeys following addition of catalase to remove the hydrogen peroxide action [35, 36], such as methylglyoxal [37] (in Manuka honey from New Zealand), bee-defensin-1 [10, 25] (a peptide secreted by hypopharyngeal glands of bees) and melanoidins [38]. Moreover, volatile components, phenolic compounds, organic acids, lysozyme, beeswax, nectar, pollen and propolis found in small quantities are outstanding chemical factors which 
ensure anti-infectious activity to honey. Also, part of the anti-infectious properties can be related to biochemical components of plant origin, such as different oligosaccharides [10, 11].

Floral honey is made by bees from nectar collected from very various floral sources, and consequently, its antibacterial potency can differ broadly (up to 100 times) [39] in accordance with its origin and processing. Therefore, some authors proposed that medical grade honey should be selected for anti-infectious use according to the antibacterial capacity determined by bacteriological tests [10, 40].

On the other hand, clinical trials established that floral origin and antibacterial potency of honey do not seem to correlate with any difference in effectiveness in the therapy of burns [41]. It was noted that applying honey determines a reduction in inflammation and scar contractures. Antioxidant effect of honey in neutralizing free radicals, together with antibacterial action, low $\mathrm{pH}$, high viscosity, hygroscopic effect and moist environment, all contribute to the efficiency of honey in burns treatment [41, 42].

Apart from its significant anti-infectious activity, honey has other related advantages, such as lack of side effects (considerable disadvantages of antibiotics), economic benefits by decreasing total cost of treatment and hospitalization time, remarkably low possibility of developing resistant strains, inasmuch as pathogenic microorganisms are simultaneously injured through a lot of mechanisms: high osmotic pressure, low $\mathrm{pH}$, hydrogen peroxide, bee defensin-1, methylglyoxal and other phytochemicals [10].

\subsection{The Anti-inflammatory Activity of Honey}

Besides the anti-infectious activity of honey, a lot of studies highlighted its anti-inflammatory, anti-edematous and anti-exudative activities, as shown by assessment of wound evolution [30, 43-48], biochemical tests of indicators of inflammation (decreased malondialdehyde and lipid peroxide levels) [49-51] and histopathology exams (decrease of inflammatory cells) [43].

Possible mechanisms of inflammatory activity can be: (1) inhibition of complement [52]; (2) inhibition of nitric oxide production by macrophages [53]; (3) inactivation and suppression of reactive oxygen species (ROS) by phagocytes [52, 54-57]; (4) decrease of thermal injury-induced oxidative stress by controlling free radicals that are induced in the burned wound [50].

Phytochemical components with anti-inflammatory effect are phenolic acids, flavonoids [53] and an anti-inflammatory factor identified as apalbumina-1, a protein secreted by bees [58]. The reduction of fibrosis and hypertrophic scarring are determined by the anti-inflammatory effect and suppression of ROS, which overstimulate fibroblasts $[45,59]$. In contrast, synthetic anti-inflammatory drugs do not support wound healing (non-steroidal anti-inflammatory drugs are cytotoxic agents and corticosteroids inhibit the growth of epithelium) [23].

In some experimentally induced burns, no apparent infection was present, but honey has continued to cause a decrease in inflammation. This fact shows that the anti-inflammatory activity of honey is a direct action and not a side effect of removing infection due to its anti-infectious activity [60].

\subsection{The Antioxidant Activity of Honey}

Studies have also revealed an intrinsic antioxidant activity of honey, by controlling free radicals [48] and ROS [61]. ROS act as messengers that enhance the inflammatory response and this process can be prevented by various antioxidant substances [62], which are abundantly present in honey [61, 63]. Also, ROS produced by phagocytes in inflamed tissues activate proteases that are normally inactive [64, 65], and activated proteases digest extracellular matrix and cell growth factors needed for tissue repair [23, 66].

\subsection{Physical Properties and Moist Wound Healing}

Besides its own anti-infectious, anti-inflammatory and antioxidant actions, honey provides physical 
barrier and moist local environment, due to its high viscosity and of fluids drawing by osmosis. This stimulates wound healing, because wounds heal faster if kept moist, than if left to dry and form a scab [23, 24, 67, 68]. A moist wound environment ensures epithelial cells growth, fibroblasts contraction to approach the wound edges, as well as non-adherence of dressing to the wound, easy and painless changing of dressings, without risk of injury and breaking the newly formed epithelium. Also, a local moist environment enables the protein-digesting enzymes in the wound tissues to loosen any scab and dead tissue [23, 24].

\subsection{Debriding Activity of Honey}

Moreover, honey has a wound debriding action, evidenced in clinical trials [43-48, 69-73]. Honey activates plasminogen and increases plasmin activity, which lyses fibrin attaching slough, by suppression of the macrophage plasminogen activation inhibitor. Plasmin digests fibrin, which attaches debris on wound surface, but does not digest collagen extracellular matrix which is essential for tissue repair [23].

\subsection{The Nutritional Activity of Honey}

Furthermore, honey has nutritional action in the wound, indirectly through osmotic drainage, which brings nutrients necessary for wound healing from interstitial fluid, but also directly through input of easily metabolisable carbohydrate, amino acids, vitamins and minerals [23, 43, 74]. Studies have evidenced that wounds heal faster if they are applied a mixture of nutrients [75-77]. Honey provides glucose support for epithelial cells, which require intern reserve of carbohydrates for energy migration over the wound surface to restore epithelial sheath [78], for leukocytes, for the respiratory (oxidative) burst that produces hydrogen peroxide, the dominant component of macrophages antibacterial activity, and for glycolysis, which is the major mechanism of energy production by macrophages, allowing them to function in damaged tissues and exudates, where the amount of oxygen is often limited [24].

\subsection{Osmotic Flow and Wound Drainage}

In addition, high osmolarity of honey causes interstitial fluid drainage, which provides nutritional support for tissue regeneration. Otherwise, the new formed tissue can only grow around points of angiogenesis, which are seen as granulation [74]. Inducing the osmotic flow also contribute to lifting and removing waste and debris from the wound, which may even eliminate the need for surgical debridement [74]. It also contributes to the lack of adherence of the dressing to the wound. If honey is in sufficient amount, it can form a fluid layer in contact with the surface of the wound. This ensures easy raising of dressings and removal of any residue by simple rinsing. Thus, dressings change is accomplished without pain and without breaking the newly formed tissue [75].

\subsection{The Deodorizing Activity of Honey}

Honey has also a deodorizing property. High carbohydrate amounts delivered by honey can be used by bacteria in preference to amino acids [79] in the serum and dead cells, thus forming lactic acid instead of ammonia, various amines and sulfur compounds that are the cause of malodor in burns [74] .

\subsection{Evidence from Animal Experiments}

Wound healing is one of the most studied and most effective use of honey [11], which was highlighted both through experiments on laboratory animals and through clinical studies.

Besides increasing the rate of healing compared to control [60, 67, 74, 80-83], animal experiments with standard wounds allowed better comparison of results, histopathological examinations of wounds [60] and objectivity of results by eliminating the placebo effect, possibly found in clinical trials. Moreover, they highlighted the importance of using only natural floral honeys, properly harvested and processed [67, 83] and the synergistic effect of concomitant oral 
administration of honey in promoting wound epithelialization [81, 82]. Ingested honey provides the patient an energetic boost trough high amount of easily absorbable sugars, as well as many important health-promoting elements, such as antioxidants, microelements, trace elements and vitamins [10].

\subsection{Evidence from Clinical Trials}

Many controlled clinical trials were performed with some being randomized, which compared honey dressings with different products (silver sulfadiazine, betadine, saline compresses, paraffin dressings, hydrogel, etc.) for therapy of different types of wounds, including burns of various depths [23, 60]. Almost all types of wounds responded favorably to application of honey dressings: abrasions, abscesses, amputation stumps, burns, fistulas, traumatic, surgical and infected wounds, cracked nipples, wounds of abdominal wall and perineum, diabetic, malignant, leprosy, traumatic, decubitus, cervical, varicose and sickle cells ulcers [11].

Based on 26 eligible randomized and quasi-randomized trials with total of 3,011 participants, the meta-analysis of Cochrane systematic review of honey as a topical treatment for wounds, published in 2015 [84], found robust evidence that honey is able to heal partial thickness burns more quickly than conventional treatment (which included polyurethane film, paraffin gauze, soframycin-impregnated gauze, sterile linen and leaving the burns exposed) and infected post-operative wounds more quickly than antiseptics and gauze.

Application of honey dressings on various types of wounds leads to stimulation of wound healing, quick removal of infection, cleansing of debris and necrotic tissue, decrease of inflammation, deodorization of very smelly wounds, stimulation of wound regeneration through development of clean granulation tissue and progressive epithelialization, with the minimal scar formation [11, 27, 44, 45, 48, 69, 85].

Honey was observed to exert calming and soothing action when applied to wounds [30, 45] and to reduce pain from burns [45]. Due to osmotic outflow after the application of honey, dirt and debris are progressively lifted from the wound bed. Thus, the non-adherent dressings enable easy removal, without any discomfort or inconvenience [11]. Honey dressings were reported to be easy to apply and remove [70, 86, 87], without adhesions [88] or bleeding [45], any residual amount of honey being easily removed by simply rinsing [29].

Studies highlighted that honey did not cause any local pain on dressing [88, 89] or caused only a momentary stinging [89], was not irritating [47, 89], did not cause any allergic reaction $[59,70,85]$ and had no harmful effects on tissues [47, 70, 85, 89].

Moreover, honey dressings have revealed economic benefits by lower direct costs compared to conventional treatments [70, 90], by decreasing the use of antibiotics [91], the healing and hospitalization time [70, 85, 91].

\subsection{Personal Experience with L-Mesitran Dressings}

As a result of multiple properties and actions favorable to wound healing, and extending the previous experience with honey dressings, L-Mesitran range of products, registered in the EU since 2002 as medical devices, was used. These wound care dressings from Holland were the first to acquire European conformity (CE) marking and FDA approval. These dressings are based on medical grade honey as the main active component, together with other ingredients, such as hypoallergenic medicinal lanolin, vitamins $\mathrm{C}$ and $\mathrm{E}$. These sterilized preparations are available in the form of an ointment or impregnated dressings, to be selected and used in various clinical situations [92]. They were applied for various skin lesions after wound cleansing, and exerted quickly a favorable action on healing of burns and other types of wounds, sometimes in combination with surgical treatment, being applied in these cases before or after surgery.

As described in clinical trials, the procedure for 
applying medicinal honey dressings was as follows [74]:

(1) Initial debridement and surgical toilet of the wound, to remove necrotic tissue, open abscesses and drain septic collections [46, 48, 70, 86, 91]. This stage was especially necessary in the case of burns and infected, necrotic wounds;

(2) Wound cleansing with saline and antiseptic solutions, as hydrogen peroxide and betadine [43, 45-47, 59, 69, 71, 93];

(3) Outspreading the L-Mesitran ointment on the wound and covering with a dry sterile gauze dressing. Alternatively, medical grade honey can be spread on sterile gauze and then applied over the wound [18, 48]. As a useful alternative to cotton dressings, special types of dressings impregnated with medical grade honey were used in some clinical situations, such as tulle and hydroactive dressings from L-Mesitran range of products. The wound cavities were filled with medical grade honey or with honey-impregnated dressings [91] and then covered with gauze [70, 89];

(4) Changing of honey dressings was practiced mostly daily [69-71, 86, 89, 90], but also once every $2-3 \mathrm{~d}[43,45,47,59,87]$, according to the appearance and evolution of wounds. Thus, the clean wounds with reduced exudate and good evolution require less frequent change.

According to literature data which emphasized the favorable activity of honey on healing of partial thickness burns, superior to conventional dressings [84], medical grade honey dressings were predominantly used in patients with burn wounds. When surgical treatment was performed for patients with deep burns (deep partial thickness or full thickness burns), the honey based dressings were applied before or after surgery.

In the following, some typical examples of patients treated with medical grade honey dressings, from L-Mesitran range of products, will be present. Some patients received additional medication, such as antibiotics, anticoagulants, nonsteroidal anti-inflammatory drugs (NSAIDS), analgesics, hydroelectrolitic intravenous solutions in larger burns.

\subsubsection{Case Study No. 1}

Man was 65 years old, with flame burn injury 2-3 degree, $20 \%$ total burn surface area (TBSA) on left hand and left lower limb. In this case, L-Mesitran products were applied postoperatively, after serial wound debridements and skin grafting of the left leg (Fig. 1).

L-Mesitran ointment was applied on the partial tibia exposure in the proximal third of the left leg, while L-Mesitran Net and Tulle were applied together on post burn wounds of the left leg (Fig. 2).

Progressive wounds epithelization was noticed after three weeks, including tibia exposure (Fig. 3), with complete wounds closure at four weeks (Fig. 4).

\subsubsection{Case Study No. 2}

Woman was 83 years old, with scald burn injury 2-3 degree, on left arm, shoulder and hemi thorax. After $26 \mathrm{~d}$ of conservative (non-surgical) treatment, necrotic and infected tissues were still present in the wound (Fig. 5).

In this case, L-Mesitran ointment was applied preoperatively and after only $6 \mathrm{~d}$, efficient wound

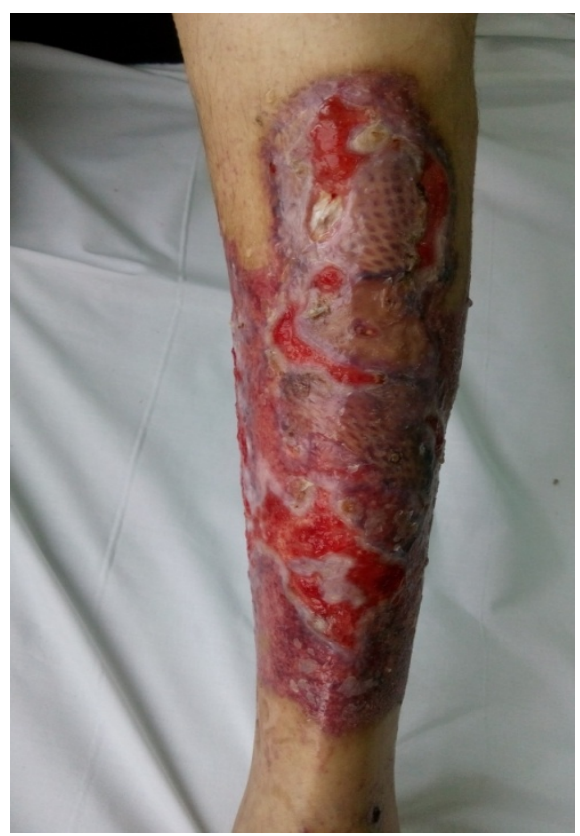

Fig. 1 Burned left leg, after surgery and before application of L-Mesitran products. 
Honey, Food and Medicine: Scientific Rationale and Practical Efficiency in External Administration of Medicinal Honey for Wound Healing

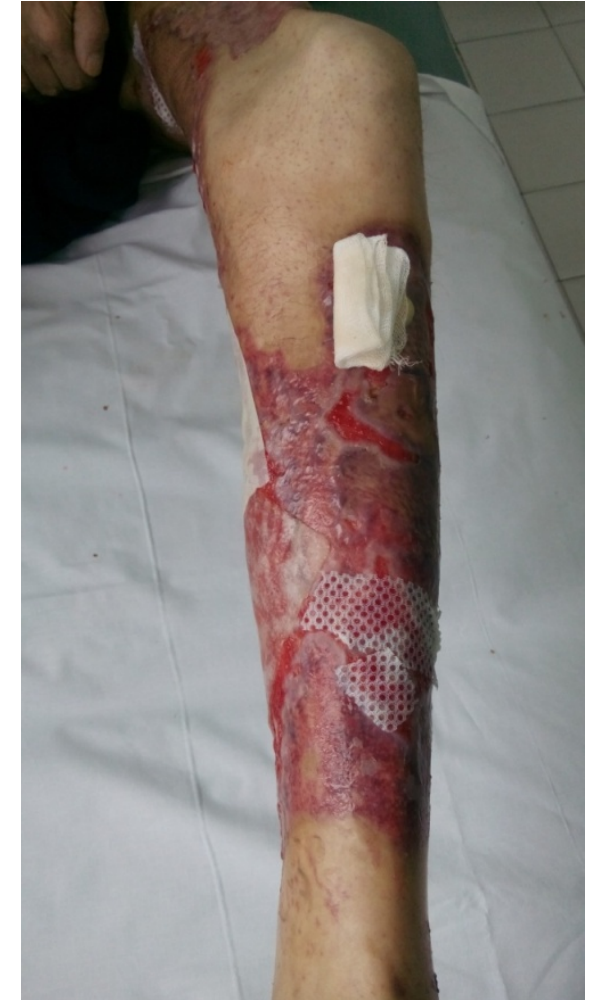

Fig. 2 L-Mesitran ointment applied in the proximal third of the left leg.

L-Mesitran Tulle applied in the antero-medial side and L-Mesitran Net applied in the antero-lateral side.

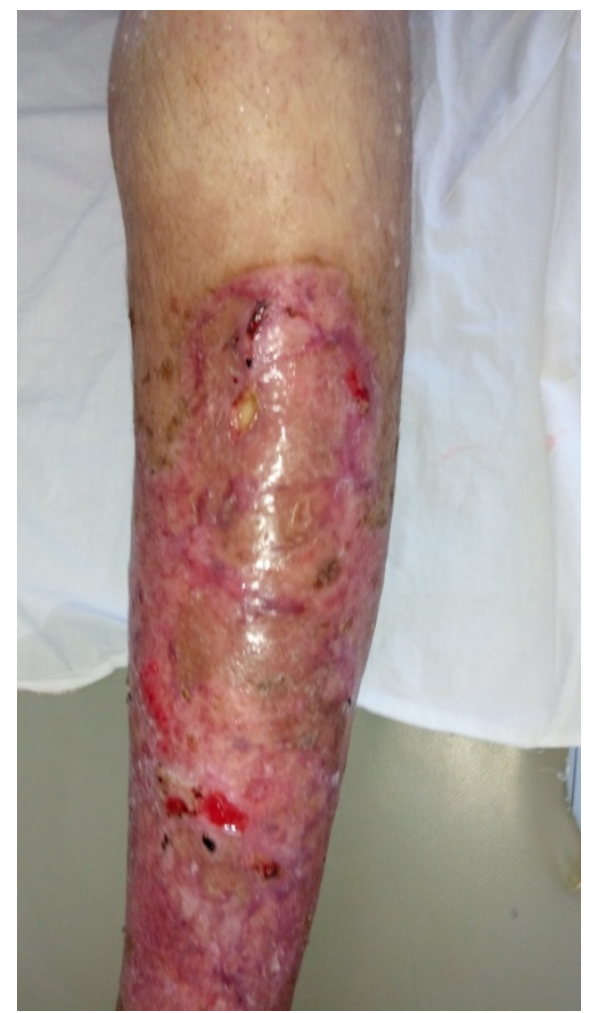

Fig. 3 Advancing epithelization after three weeks.

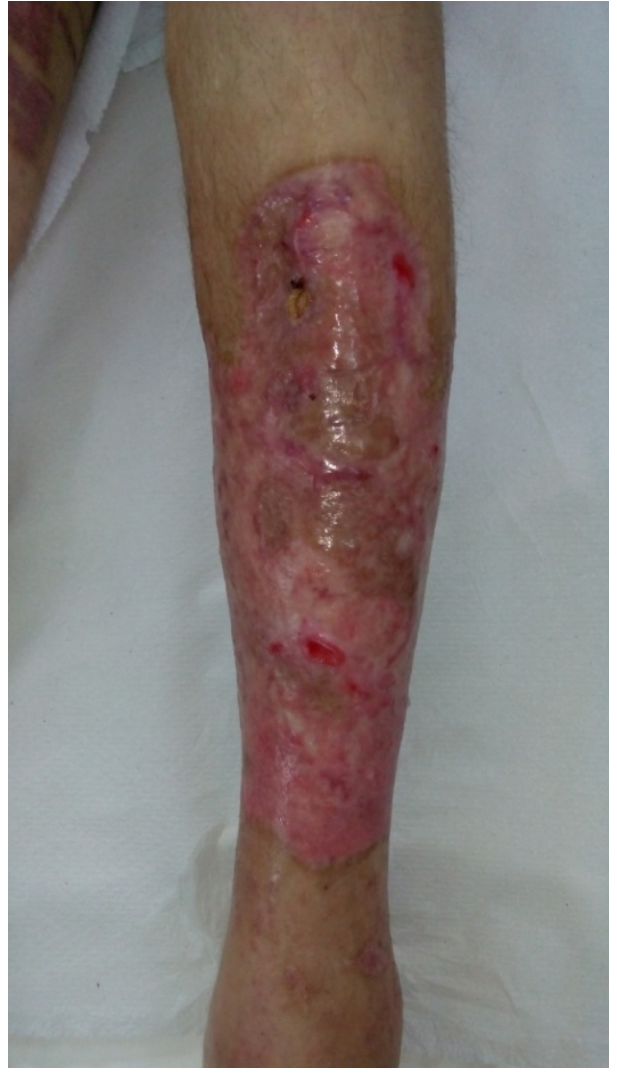

Fig. 4 Complete wound closure at four weeks.

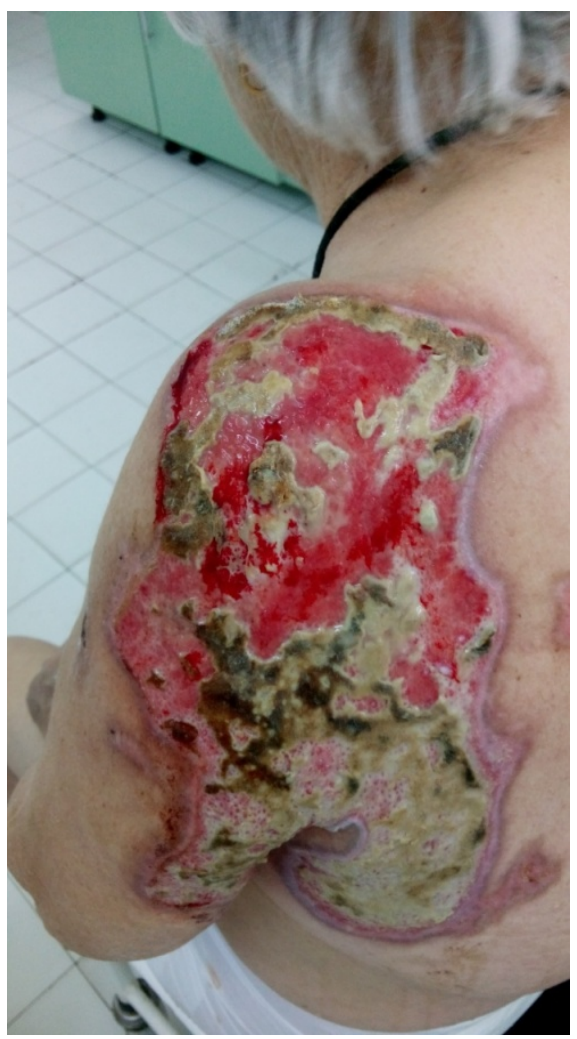

Fig. 5 After $26 \mathrm{~d}$ of conservative treatment and before application of L-Mesitran ointment. 
debridement was observed, without any sign of infection. In the upper part of the wound, on the left shoulder, wound bed was granulated and prepared for skin grafting (Fig. 6). The patient was subsequently skin grafted, with good evolution and integration of the partial-thickness skin graft.

\subsubsection{Case Study No. 3}

Woman was 49 years old, with scald burn injury 2-3 degree, on left foot (Fig. 7). Following initial burn wound debridement, L-Mesitran soft ointment was applied daily, after wound cleansing. Almost complete epithelization appeared after only $5 \mathrm{~d}$ (Fig. 8).

\subsubsection{Case Study No. 4}

Man was 62 years old, with right bimalleolar fracture, treated by the orthopedic surgeon through open reduction and internal fixation. Internal malleolar wound dehiscence appeared one week after the orthopedic operation (Fig. 9).

Seven days after the application of L-Mesitran Soft, wound dehiscence significantly diminished through

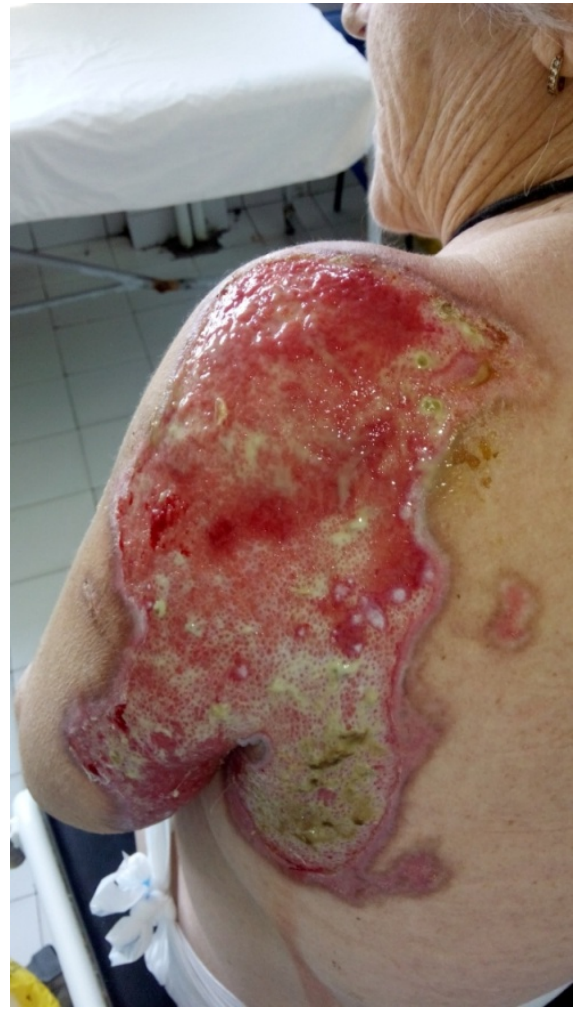

Fig. 6 Wound debridement after only $6 \mathrm{~d}$ and preparation of the left shoulder for skin grafting.

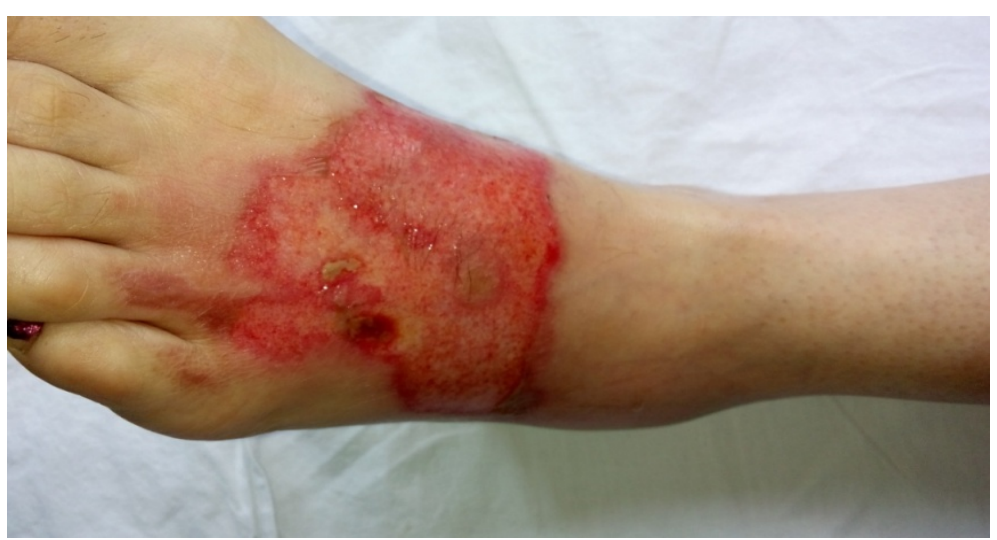

Fig. 7 Left foot, after initial burn wound debridement and before application of L-Mesitran Soft.

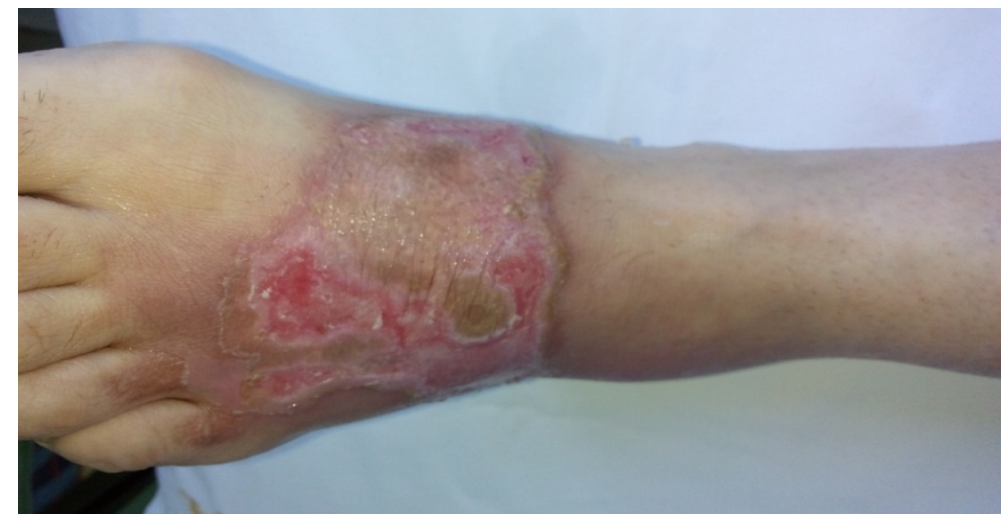

Fig. 8 Left foot, after $5 \mathrm{~d}$ of therapy with L-Mesitran Soft. 


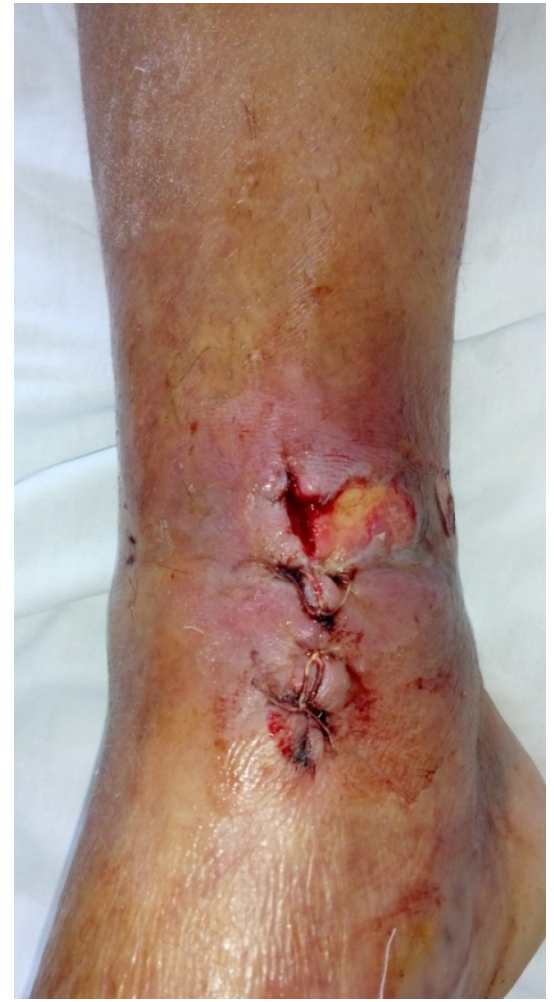

Fig. 9 Internal malleolar wound dehiscence and ankle inflammation, before application of L-Mesitran Soft ointment.

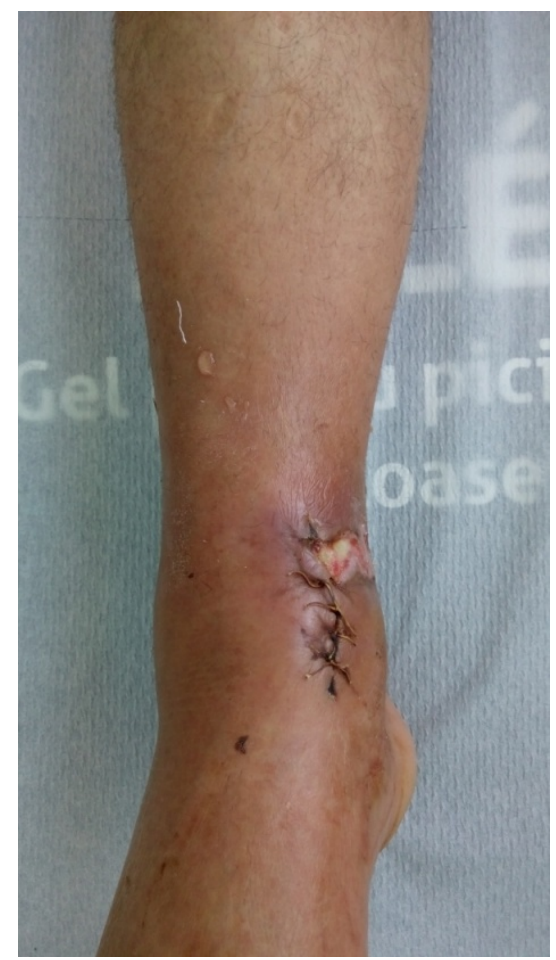

Fig. 10 Wound dehiscence reduction by marginal epithelization and remission of ankle inflammation, after only $7 \mathrm{~d}$. marginal epithelization and ankle inflammation disappeared (Fig. 10).

These case studies are representative for clinical indications and favorable outcomes of treatment with medical grade honey based products: partial thickness burns and infected wounds [83]. In burned wounds, honey based products can be used as topical therapy in conservative (nonsurgical) approach (case study No. 3) or they can be applied as complementary (adjuvant) therapy, which prepares the burned wound for skin grafting (case study No. 2) or completes the results obtained after surgery (case study No. 1).

Also, medical grade honey based products were successfully used for skin grafts integration and healing of donor sites after harvesting of partial thickness skin grafts.

After application of medical grade honey, no side effects have been noted, except transient pain in some sensitive patients, which was easily managed by simple measures, such as: decreasing the quantity of ointment, cleansing or dilution with sterile saline solution, slightly wet subsequent dressing and common administering a painkiller.

\section{Conclusions}

Laboratory research and clinical studies have highlighted a broad range of activities provided by honey: anti-infectious, anti-inflammatory, antiexudative, antioxidant, wound healing, wound debriding, wound drainage, nutritional and deodorizing properties.

The products based on medical grade honey can be administered in the topical treatment of various skin lesions, as a result of the favorable effects exerted by medicinal honey, along with the other ingredients. The complex product range L-Mesitran, based on medicinal and sterilized honey, has proven effective, safe and easy to apply, in different patients and clinical situations.

Scientific studies and clinical utilization confirm the increasing interest and confidence in honey. 

External Administration of Medicinal Honey for Wound Healing

Besides promoting sustainable agriculture, honey used for wound healing is an integrative form of therapy, with a biologic product with complex range of properties. However, further clinical studies and controlled trials are required to establish the best indications and methods of administration for each type of wounds.

\section{References}

[1] Mateescu, C. 2011. Apitherapy or How to Use Beehive Products for Health. Bucharest: Fiat Lux, 19-21. (in Romanian)

[2] Molan, P. C. 2006. "The Evidence Supporting the Use of Honey as a Wound Dressing.” Int. J. Low Extrem. Wounds 5 (1): 40-54.

[3] Merckoll, P., Jonassen, T. Ø., Vad, M. E., Jeansson, S. L., and Melby, K. K. 2009. "Bacteria, Biofilm and Honey: A Study of the Effects of Honey on Planktonic and Biofilm-Embedded Chronic Wound Bacteria.” Scand. J. Infect. Dis. 41 (5): 341-7.

[4] Blair, S. E., Cokcetin, N. N., Harry, E. J., and Carter, D. A. 2009. "The Unusual Antibacterial Activity of Medical-Grade Leptospermum Honey: Antibacterial Spectrum, Resistance and Transcriptome Analysis.” Eur. J. Clin. Microbiol. Infect. Dis. 28 (10): 1199-208.

[5] Vandamme, L., Heyneman, A., Hoeksema, H., Verbelen, J., and Monstrey, S. 2013. "Honey in Modern Wound Care: A Systematic Review.” Burns 39 (8): 1514-25.

[6] Seckam, A., and Cooper, R. 2013. "Understanding How Honey Impacts on Wounds: An Update on Recent Research Findings.” Wounds International 4 (1): 20-4.

[7] Lu, J., Carter, D. A., Turnbull, L., Rosendale, D., Hedderley, D., Sttephens, J., Gannabathula, S., Steinhorn, G., Schlothauer, R. C., Whitchurch, C. B., and Harry, E. J. 2013. "The Effect of New Zealand Kanuka, Manuka and Clover Honeys on Bacterial Growth Dynamics and Cellular Morphology Varies according to the Species.” PLOS ONE 8 (2): e55898.

[8] Molan, P. C. 2001. "Honey as a Topical Antibacterial Agent for Treatment of Infected Wounds.” World Wide Wounds (Internet). Accessed July 10, 2017. http://www.worldwidewounds.com/2001/november/Mola n/honey-as-topical-agent.html.

[9] Brady, N. F., Molan, P. C., and Harfoot, C. G. 1997. "The Sensitivity of Dermatophytes to the Antimicrobial Activity of Manuka Honey and Other Honey.” Pharm. Sci. 2: 1-3.

[10] Szweda, P. 2017. “Antimicrobial Activity of Honey.” In Honey Analysis, edited by Toledo, V. A. A. Rijeka, Croatia: InTech, 3-15.
[11] Eteraf-Oskouei, T., and Najafi, M. 2013. "Traditional and Modern Uses of Natural Honey in Human Diseases: A Review.” Iran. J. Basic Med. Sci. 16 (6): 731-42.

[12] George, N. M., and Cutting, K. F. 2007. "Antibacterial Honey (Medihoney ${ }^{\mathrm{TM}}$ ): In Vitro Activity against Clinical Isolates of MRSA, VRE and Other Multiresistant Gram-negative Organisms Including Pseudomonas aeruginosa.” Wounds 19 (9): 231-6.

[13] Cooper, R. A., and Molan, P. C. 1999. "The Use of Honey as an Antiseptic in Managing Pseudomonas Infection.” J. Wound Care 8: 161-4.

[14] Subrahmanyam, M., Hemmady, A., and Pawar, S. G. 2001. "Antibacterial Activity of Honey on Bacteria Isolated from Wounds.” Ann. Burns Fire Disasters 14 (1): 22.

[15] Molan, P. C. 2009. "Honey: Antimicrobial Actions and Role in Disease Management." In New Strategies Combating Bacterial Infection, edited by Ahmad, I., and Aqil, F. Weinheim, Germany: Wiley VCH, 229-53.

[16] Bang, L., Buntting, C., and Molan, P. 2003. “The Effect of Dilution on the Rate of Hydrogen Peroxide Production in Honey and Its Implications for Wound Healing.” J. Altern. Complement Med. 9 (2): 267-73.

[17] Cooper, R. A., Jenkins, L., Henriques, A. F. M., Duggan, R. S., and Burton, N. F. 2010. "Absence of Bacterial Resistance to Medical-Grade Manuka Honey.” Eur. J. Microbiol. Infect. Dis. 29 (10): 1237-41.

[18] Okhiria, O. A., Henriques, A., Burton, N. F., Peters, A., and Cooper, R. A. 2009. "Honey Modulates Biofilms of Pseudomonas aeruginosa in a Time and Dose Dependent Manner.” J. Api-Product and Api-Medical Science 1 (1): 6-10.

[19] Alandejani, T., Marsan, J., Ferris, W., Slinger, R., and Chan, F. 2009. "Effectiveness of Honey on Staphylococcus aureus and Pseudomonas aeruginosa Biofilms.” Otolaryngology-Head and Neck Surgery 141 (1): 114-8.

[20] Maddocks, S. E., Lopez, M. S., Rowlands, R. S., and Cooper, R. A. 2012. "Manuka Honey Inhibits the Development of Streptococcus pyogenes Biofilms and Causes Reduced Expression of Two Fibronectin Binding Proteins.” Microbiology 158: 781-90.

[21] Cooper, R., Jenkins, L., and Hooper, S. 2014. "Inhibition of Biofilms of Pseudomonas aeruginosa by Medihoney in Vitro.” J. Wound Care 23 (3): 93-102.

[22] Hill, K. E., Malic, S., and McKee, R. 2010. "An in Vitro Model of Chronic Wound Biofilms to Test Wound Dressings and Assess Antimicrobial Susceptibilities.” J. Antimicrob Chemother. 65 (6): 1195-206.

[23] Molan, P. C. 2011. "The Evidence and the Rationale for the Use of Honey as a Wound Dressing." Wound Practice and Research 19 (4): 204-20.

[24] Zbuchea, A. 2014. "Up-to-Date Use of Honey for Burns 

External Administration of Medicinal Honey for Wound Healing

Treatment.” Ann. Burns Fire Disasters 27 (1): 22-30.

[25] Kwakman, P. H., Velde, A. A., De Boer, L., Speijer, D., Vandenbroucke-Grauls, C. M., and Zaat, S. A. 2010. “How Honey Kills Bacteria.” FASEB J. 24 (7): 2576-82.

[26] Lee, H., Churey, J. J., and Worobo, R. W. 2008. "Antimicrobial Activity of Bacterial Isolates from Different Floral Sources of Honey.” Int. J. Food Microbiol. 126 (1-2): 240-4.

[27] Schencke, C., Vasquez, B., Sandoval, C., and Del Sol, M. 2016. "The Role of Honey in the Morpho-physiologic Processes of Wounds Repair.” Int. J. Morphol. 34 (1): 385-95. (in Spanish)

[28] Sami, A. N., Mehmood, N., Qureshi, M. A., Zeeshan, H. K., Malik-Irfan, A., and Iqbal-Khan, M. 2011. "Honey Compared with Silver Sulfadiazine as Burn Wound Dressing.” Ann. Pak. Inst. Med. Sci. 7 (1): 22-5.

[29] Green, A. E. 1988. "Wound Healing Properties of Honey." Br. J. Surg. 75 (12): 1278.

[30] Keast-Butler, J. 1980. "Honey for Necrotic Malignant Breast Ulcers.” Lancet 316 (8198): 809.

[31] Mossel, D. A. 1980. "Honey for Necrotic Breast Ulcers.” Lancet 316 (8203): 1091.

[32] Chirife, J., Herszage, L., Joseph, A., and Kohn, E. S. 1983. "In Vitro Study of Bacterial Growth Inhibition in Concentrated Sugar Solutions: Microbiological Basis for the Use of Sugar in Treating Infected Wounds.” Antimicrob. Agents Chemother. 23 (5): 766-73.

[33] Gupta, S. K., Singh, H., Varshney, A. C., and Prakash, P. 1992. "Therapeutic Efficacy of Honey in Infected Wounds in Buffaloes.” Indian J. Anim. Sci. 62 (6): 521-3.

[34] White, J. W., Subers, M. H., and Schepartz, A. I. 1963. "The Identification of Inhibine, the Antibacterial Factor in Honey, as Hydrogen Peroxide and Its Origin in a Honey Glucose-Oxidase System.” Biochimica et Biophysica Acta 73: 57-70.

[35] Allen, K. L., Molan, P. C., and Reid, G. M. 1991. “A Survey of the Antibacterial Activity of Some New Zealand Honeys.” J. Pharm. Pharmacol. 43 (12): 817-22.

[36] Adcock, D. 1962. "The Effect of Catalase on the Inhibine and Peroxide Values of Various Honeys.” J. Apic. Res. 1: 38-40.

[37] Mavric, E., Wittmann, S., Barth, G., and Henle, T. 2008. "Identification and Quantification of Methylglyoxal as the Dominant Antibacterial Constituent of Manuka (Leptospermum scoparium) Honeys from New Zealand.” Mol. Nutr. Food Res. 52: 483-9.

[38] Rufian-Henares, J. A., and Morales, F. J. 2007. "Functional Properties of Melanoidins: In Vitro Antioxidant, Antimicrobial and Antihypertensive Activities.” Food Research Int. 40: 995-1002.

[39] D’Agostino Barbaro, A., La Rosa, C., and Zanelli, C. 1961. “Antibacterial Activity of Sicilian Honey.” Quad. Nutr. 21
(1-2): 30-44. (in Italian)

[40] Radwan, S. S., El-Essawy, A., and Sarhan, M. 1984. "Experimental Evidence for the Occurrence in Honey of Specific Substances Active against Microorganisms." Zentralbl. Mikrobiol. 139 (4): 249-55.

[41] Subrahmanyam, M. 2007. "Topical Application of Honey for Burn Wound Treatment-An Overview.” Ann. Burns Fire Disasters 20 (3): 137-9.

[42] Subrahmanyam, M., Hemmady, A., and Pawar, S. G. 2003 "The Sensitivity to Honey of Multidrug-Resistant Pseudomonas aeruginosa from Infected Burns.” Ann. Burns Fire Disasters 16 (2): 84-6.

[43] Subrahmanyam, M. 1998. “A Prospective Randomised Clinical and Histopathological Study of Superficial Burn Wound Healing with Honey and Silver Sulfadiazine.” Burns 24 (2): 157-61.

[44] Efem, S. E. E. 1993. "Recent Advances in the Management of Fournier's Gangrene: Preliminary Observations.” Surgery 113 (2): 200-4.

[45] Subrahmanyam, M. 1993. "Honey Impregnated Gauze versus Polyurethane Film (OpSite ${ }^{\mathrm{R}}$ ) in the Treatment of Burns-A Prospective Randomised Study.” Br. J. Plast. Surg. 46 (4): 322-3.

[46] Dumronglert, E. 1983. "A Follow-Up Study of Chronic Wound Healing Dressing with Pure Natural Honey." J. Nat. Res. Counc. Thail. 15 (2): 39-66.

[47] Subrahmanyam, M. 1996. "Honey Dressing versus Boiled Potato Peel in the Treatment of Burns: A Prospective Randomised Study.” Burns 22 (6): 491-3.

[48] Hejase, M. J., Simonin, J. E., Bihrle, R., and Coogan, C. L. 1996. "Genital Fournier's Gangrene: Experience with 38 Patients.” Urology 47 (5): 734-9.

[49] Subrahmanyam, M., Sahapure, A. G., Nagane, N. S., Bhagwat, V. R., and Ganu, J. V. 2001. "Effects of Topical Application of Honey on Burn Wound Healing." Ann. Burns Fire Disasters 14 (3): 143-5.

[50] Subrahmanyam, M., Sahapure, A. G., Nagane, N. S., Bhagwat, V. R., and Ganu, J. V. 2003.” Free Radical Control: The Main Mechanism of the Action of Honey in Burns.” Ann. Burns Fire Disasters 16 (3): 135-7.

[51] Nagane, N. S., Ganu, J. V., Bhagwat, V. R., and Subrahmanyam, M. 2004. "Efficacy of Topical Honey Therapy against Silver Sulphadiazine Treatment in Burns: A Biochemical Study.” Indian J. Clin. Biochem. 19 (2): 173-6.

[52] Van den Berg, A. J., Van Den Worm, E., Van Ufford, H. C., Halkes, S. B., Hoekstra, M. J., and Beukelman, C. J. 2008. "An in Vitro Examination of the Antioxidant and Anti-inflammatory Properties of Buckwheat Honey.” $J$. Wound Care 17 (4): 172-8.

[53] Kassim, M., Achoui, M., Mustafa, M. R., Mohd, M. A., and Yusoff, K. M. 2010. "Ellagic Acid, Phenolic Acids 
and Flavonoids in Malaysian Honey Extracts Demonstrate in Vitro Anti-inflammatory Activity.” Nutr. Res. 30 (9): 650-9.

[54] Tonks, A., Cooper, R. A., Price, A. J., Molan, P. C., and Jones, K. P. 2001. "Stimulation of TNF-Alpha Release in Monocytes by Honey.” Cytokine 14 (4): 240-2.

[55] Henriques, A., Jackson, S., Cooper, R., and Burtom, N. 2006. "Free Radical Production and Quenching in Honeys with Wound Healing Potential.” J. Antimicrob. Chemother. 58 (4): 773-7.

[56] Mesaik, M. A., Azim, M. K., and Mohiuddin, S. 2008. "Honey Modulates Oxidative Burst of Professional Phagocytes.” Phytother. Res. 22 (10): 1404-8.

[57] Ahmad, A., Khan, R. A., and Mesaik, M. A. 2009. "Anti-inflammatory Effect of Natural Honey on Bovine Thrombin-Induced Oxidative Burst in Phagocytes.” Phytother. Res. 23 (6): 801-8.

[58] Molan, P. 2012. "Honey Anti-inflammatory Factor Identified.” New Zealand Beekeeper, September 2012.

[59] Subrahmanyam, M. 1994. "Honey Impregnated Gauze versus Amniotic Membrane in the Treatment of Burns.” Burns 20 (4): 331-3.

[60] Molan, P. C. 2006. "The Evidence Supporting the Use of Honey as a Wound Dressing.” Int. J. Low Extrem. Wounds 5 (1): 40-54.

[61] Inoue, K., Murayama, S., Seshimo, F., Takeba, K., Yoshimura, Y., and Nakazawa, H. 2005. "Identification of Phenolic Compound in Manuka Honey as Specific Superoxide Anion Radical Scavenger Using Electron Spin Resonance (ESR) and Liquid Chromatography with Colorimetric Array Detection.” J. Sci. Food Agric. 85 (5): 872-8.

[62] Ma, Q., Kinneer, K., Ye, J. P., and Chen, B. J. 2003. "Inhibition of Nuclear Factor Kappa B by Phenolic Antioxidants: Interplay between Antioxidant Signaling and Inflammatory Cytokine Expression.” Mol. Pharmacol. 64 (2): 211-9.

[63] Tan, S. T., Holland, P. T., Wilkins, A. L., and Molan, P. C. 1988. "Extractives from New Zealand Honeys. 1. White Clover, Manuka and Kanuka Unifloral Honeys.” J. Agric. Food Chem. 36 (3): 453-60.

[64] Peppin, G. J., and Weiss, S. J. 1986. “Activation of the Endogenous Metalloproteinase, Gelatinase, by Triggered Human Neutrophils.” Proc. Nat. Acad. Sci. USA 83 (12): 4322-6.

[65] Weiss, S. J., Peppin, G., Ortiz, X., Ragsdale, C., and Test, S. T. 1985. "Oxidative Autoactivation of Latent Collagenase by Human Neutrophils.” Science 227 (4688): 747-9.

[66] Toriseva, M., and Kahari, V. M. 2009. "Proteinases in Cutaneous Wound Healing.” Cell Mol. Life Sci. 66 (2): 203-24.
[67] Kandil, A., El-Banby, M., Abdel-Wahed, K., Sehli, G. A., and Ezzat, N. 1987. "Healing Effect of True Floral and False Nonfloral Honey on Medical Wounds.” J. Drug Res. (Cairo) 17 (1-2): 71-6.

[68] Winter, G. D. 1962. "Formation of the Scab and the Rate of Epithelialization of Superficial Wounds in the Skin of the Young Domestic Pig.” Nature 193: 293-4.

[69] Subrahmanyam, M. 1991. "Topical Application of Honey in Treatment of Burns.” Br. J. Surg. 78 (4): 497-8.

[70] Farouk, A., Hassan, T., Kashif, H., Khalid, S. A., Mutawali, I., and Wadi, M. 1988. "Studies on Sudanese Bee Honey: Laboratory and Clinical Evaluation.” Int. J. Crude Drug Res. 26 (3): 161-8.

[71] Ndayisaba, G., Bazira, L., Habonimana, E., and Muteganya, D. 1993. "Clinical and Bacteriological Results in Wounds Treated with Honey.” J. Orthop. Surg. 7 (2): 202-4.

[72] Molan, P. C. 2009. "Debridement of Wounds with Honey.” Journal of Wound Technology 5: 12-7.

[73] Gethin, G., and Cowman, S. 2009. "Manuka Honey vs. Hydrogel-A Prospective, Open Label, Multicentre, Randomised Controlled Trial to Compare Desloughing Efficacy and Healing Outcomes in Venous Ulcers.” J. Clin. Nurs. 18 (3): 466-74.

[74] Molan, P. C. 1998. "A Brief Review of Honey as a Clinical Dressing.” Primary Intention (The Australian Journal of Wound Management) 6 (4): 148-58.

[75] Kaufman, T., Levin, M., and Hurwitz, D. J. 1984. “The Effect of Topical Hyperalimentation on Wound Healing Rate and Granulation Tissue Formation of Experimental Deep Second Degree Burns in Guinea-Pigs.” Burns Incl. Therm. Inj. 10 (4): 252-6.

[76] Niinikoski, J., Kivisaari, J., and Viljanto, J. 1977. "Local Hyperalimentation of Experimental Granulation Tissue.” Acta Chir. Scand. 143 (4): 201-6.

[77] Silvetti, A. N. 1981. "An Effective Method of Treating Long-Enduring Wounds and Ulcers by Topical Applications of Solutions of Nutrients.” J. Dermatol. Surg. Oncol. 7 (6): 501-8.

[78] Silver, I. A. 1980. "The Physiology of Wound Healing." In Wound Healing and Wound Infection: Theory and Surgical Practice, edited by Hunt, T. K. New York: Appleton-Century-Crofts, 11-28.

[79] Nychas, G. J., Dillon, V. M., and Board, R. G. 1988. "Glucose, the Key Substrate in the Microbiological Changes in Meat and Certain Meat Products.” Biotechnol. Appl. Biochem. 10 (3): 203-31.

[80] Postmes, T. J., Bosch, M. M. C., Dutrieux, R., Van Baare, J., and Hoekstra, M. J. 1997. "Speeding Up the Healing of Burns with Honey: An Experimental Study with Histological Assessment of Wound Biopsies.” In Bee Products: Properties, Applications and Apitherapy, edited 

External Administration of Medicinal Honey for Wound Healing

by Mizrahi, A., Lensky, Y. New York: Plenum Press, 57-63.

[81] Suguna, L., Chandrakasan, G., and Thomas-Joseph, K. 1992. "Influence of Honey on Collagen Metabolism during Wound Healing in Rats.” J. Clin. Biochem. Nutr. 13 (1): 7-12.

[82] Suguna, L., Chandrakasan, G., Ramamoorthy, U., and Joseph, K. T. 1993. "Influence of Honey on Biochemical and Biophysical Parameters of Wounds in Rats.” J. Clin. Biochem. Nutr. 14 (2): 91-9.

[83] El-Banby, M., Kandil, A., Abou-Sehly, G., El-Sherif, M. E., and Abdel-Wahed, K. 1989. "Healing Effect of Floral Honey and Honey from Sugar-Fed Bees on Surgical Wounds (Animal Model)." In Proceedings of Fourth International Conference on Apiculture in Tropical Climates, 46-9.

[84] Jull, A. B., Cullum, N., Dumville, J. C., Westby, M. J., Deshpande, S., and Walker, N. 2015. "Honey as a Topical Treatment for Wounds.” Cochrane Database of Systematic Reviews. doi: 10.1002/14651858.CD005083. pub4.

[85] Phuapradit, W., and Saropala, N. 1992. "Topical Application of Honey in Treatment of Abdominal Wound
Disruption.” Australian and New Zealand J. Obstet. Gynaecol. 32 (4): 381-4.

[86] Wadi, M., Al-Amin, H., Farouq, A., Kashef, H., and Khaled, S. A. 1987. "Sudanese Bee Honey in the Treatment of Suppurating Wounds." Arab Medico 3: 16-8.

[87] Blomfield, R. 1973. "Honey for Decubitus Ulcers.” J. Am. Med. Assoc. 224 (6): 905.

[88] McInerney, R. J. F. 1990. "Honey-A Remedy Rediscovered.” J. Roy. Soc. Med. 83 (2): 127.

[89] Bulman, M. W. 1955. "Honey as a Surgical Dressing." Middlesex Hospital J. 55: 188-9.

[90] Wood, B., Rademaker, M., and Molan, P. 1997. "Manuka Honey, a Low Cost Leg Ulcer Dressing.” New Zealand Med. J. 110 (1040): 107.

[91] Armon, P. J. 1980. "The Use of Honey in the Treatment of Infected Wounds.” Trop. Doct. 10 (2): 91.

[92] L-Mesitran®. 2017. "L-Mesitran-Wound Care, Products and Clinical Studies.” Accessed July 10, 2017. http://l-mesitran.com/eu/en/home.

[93] Harris, S. 1994. "Honey for the Treatment of Superficial Wounds: A Case Report and Review.” Primary Intention 2 (4): 18-23. 